\title{
Elicitors of Plant Defense Responses from Biocontrol Strains of Trichoderma virens
}

\author{
L. E. Hanson and C. R. Howell
}

First author: U.S. Department of Agriculture-Agricultural Research Service (USDA-ARS), Sugar Beet Research Unit, Fort Collins, CO 80526; and second author: USDA-ARS, SPARC, CPRU, College Station, TX 77845.

Accepted for publication 5 September 2003

\section{ABSTRACT}

Hanson, L. E., and Howell, C. R. 2004. Elicitors of plant defense responses from biocontrol strains of Trichoderma virens. Phytopathology 94:171-176.

Effective biocontrol strains of Trichoderma virens can induce the production of defense-related compounds in the roots of cotton. Ineffective strains do not induce these compounds to significant levels. This elicittation was found to be heat stable, insoluble in chloroform, passed through a $5 \mathrm{~K}$ molecular weight cut-off (MWCO) filter, but not a $3 \mathrm{~K}$ MWCO filter, and was sensitive to treatment by proteinase K. When the active material was subjected to sodium dodecyl sulfate-polyacrylamide gel electrophoresis, several bands were present in the material from bio- control-active strains that were lacking in inactive strains. When eluted and tested for elicitation activity, with or without renaturation, four bands stimulated cotton terpenoid production. One band showed cross-reaction with an antibody to the ethylene-inducing xylanase from $T$. viride. Another band of approximately $18 \mathrm{kDa}$, gave significant stimulation of cotton terpenoid production and increased peroxidase activity in cotton radicles in all tests, with or without renaturation. The $18-\mathrm{kDa}$ protein was subjected to amino-terminal sequence analysis, and the first 19 amino acids at the amino terminus were determined to be DTVSYDTGYDNGSRSLNDV. A database homology search using the BLASTp algorithm showed the highest similarity to a serine proteinase from Fusarium sporotrichioides.
Trichoderma spp. have biocontrol activity against a number of different fungi on various hosts. On cotton, biocontrol activity has been reported against Rhizoctonia solani (12), Fusarium oxysporum f. sp. vasinfectum (26), and Verticillium dahliae (10). One proposed mechanism for biocontrol activity in Trichoderma sp. is stimulation of host defense responses (14). Induced resistance has been reported with $T$. harzianum on bean (5), an unidentified Trichoderma sp. on cucumber (18), and T. virens (Gliocladium virens) on cotton (10). Cotton seedlings treated with effective biocontrol strains of T. virens have higher levels of defense-related compounds such as terpenoids and higher peroxidase activity in the roots than seedlings treated with ineffective isolates (14).

Several fungi and oomycetes produce compounds that elicit the production of defense responses in plants $(2,4,6-9,19,21)$. The majority of these fungi are plant pathogens, but metabolites from Penicillium janczewskii elicit resistance to stem rot in melon and cotton (19) and an ethylene-inducing xylanase (EIX) produced by T. viride (3) elicits the production of the phytoalexin resveratrol in grapevine cells (1). Little is known about the potential production of other elicitors by nonpathogenic plant-associated fungi.

Culture filtrates from effective biocontrol strains of $T$. virens were found to stimulate significantly greater terpenoid levels in cotton than filtrates from noneffective strains or media alone. The purpose of this research was to isolate and identify elicitors from such $T$. virens culture filtrate.

Corresponding author: L. E. Hanson; E-mail address: lehanson@lamar.colostate.edu

\section{Publication no. P-2003-1216-01R}

This article is in the public domain and not copyrightable. It may be freely reprinted with customary crediting of the source. The American Phytopathological Society, 2004

\section{MATERIALS AND METHODS}

Parent and mutant strains of $T$. virens were stored as conidia in $25 \%$ glycerol at $-70^{\circ} \mathrm{C}$ until used. Prior to use, conidia were transferred to potato dextrose agar (PDA, Difco Laboratories, Detroit) plates containing $50 \mu \mathrm{g}$ of rifampicin per $\mathrm{ml}$, and colonies developing from them were used as a source of inoculum. Strains used in this experiment included: $T$. virens strain G6, an isolate from Texas cotton field soil with good biocontrol activity against $R$. solani (15) and two UV-induced mutants of G6 (G6-4 and G6-5) that were deficient for both mycoparasitism and gliotoxin production (provided by $\mathrm{M}$. $\mathrm{H}$. Wheeler, College Station, TX). Mutant G6-5 had good biocontrol activity against $R$. solani, but mutant G6-4 had no detectable biocontrol activity against $R$. solani (14).

To obtain culture filtrates (CFS), the Trichoderma isolates were grown in liquid shake cultures (G-10 gyratory shaker; New Brunswick Scientific Co., New Brunswick, NY) of $100 \mathrm{ml}$ of 5\% wheat bran and $1 \%$ peat moss (WBPM, pH 4.0) as described by Howell et al. (13). After 7 days incubation at $150 \mathrm{rpm}$ and $27^{\circ} \mathrm{C}$, the culture contents were filtered through Whatmann's No. 1 filter paper, and the CFS were collected. CFS were either used directly or lyophilized and brought to the desired concentration in sterile water. CFS were filter-sterilized by passage through $0.22-\mu \mathrm{m}$ filters (Sterile Acrodisc; A. Daigger \& Co., Lincolnshire, IL) and stored at $5^{\circ} \mathrm{C}$ until used. The hyphal material and peat moss particles were collected, air dried, and plated to compare growth in terms of colony-forming units for the different fungi.

Induction of terpenoids in cotton roots by culture filtrates. Cotton seeds (cv. DeltaPine 50) were surface-disinfested for $5 \mathrm{~min}$ in $2 \%$ sodium hypochlorite solution with $0.01 \%$ Triton X-100 on a rotary shaker $(200 \mathrm{rpm})$. Seeds were rinsed twice for $4 \mathrm{~h}$ in sterile distilled water and placed on filter paper moistened with distilled water in glass petri dishes wrapped in sterile aluminum foil. After 4 to 6 days, CFS were applied to the radicles of germinated seeds by pipetting $3 \mathrm{ml}$ of solution onto the radicles 
of 12 seeds per replicate, three replicates per treatment, when they were approximately $2 \mathrm{~cm}$ in length. The solution contacted the root and then saturated the sterile filter paper for continuous exposure. Controls included sterile water or sterile culture media applied to the same number of seeds and replicates. After 2 days of incubation at $26^{\circ} \mathrm{C}$, the radicles were excised from the plants. The radicles from each of the three replicates were weighed, cut into approximately 5-mm sections, and soaked for $24 \mathrm{~h}$ in a volume of $90 \%$ acetone, $9.9 \%$ water, and $0.1 \%$ ascorbic acid $(3 \mathrm{ml}$ per $g$ of tissue). The acetone extracts were drawn off by pipette and subjected to high-performance liquid chromatography (HPLC) analysis as described previously (27). The HPLC system consisted of a Model 1090 Liquid Chromatograph (Hewlett-Packard, Atlanta, GA) with a diode array detector set at $235 \mathrm{~nm}$. The solvents, methanol $\left(0.07 \% \mathrm{H}_{3} \mathrm{PO}_{4}\right)$ and $\mathrm{H}_{2} \mathrm{O}\left(0.07 \% \mathrm{H}_{3} \mathrm{PO}_{4}\right)$, were delivered using a gradient starting with $80 \% \mathrm{H}_{2} \mathrm{O}$, changing to $40 \% \mathrm{H}_{2} \mathrm{O}$ after $5 \mathrm{~min}$, and ending at $13 \% \mathrm{H}_{2} \mathrm{O}$ after $22 \mathrm{~min}$. The flow rate was $1.25 \mathrm{ml} / \mathrm{min}$.

Stimulation of peroxidase activity. 'DeltaPine 50' seed were treated with CFS as described previously. Replicate 0.55-g samples of radicles were each ground separately with a glass tissue grinder (Ace Glass, Inc., Vineland, NJ) in 1-ml aliquants of $0.1 \mathrm{M}$ phosphate buffer ( $\mathrm{pH}$ 6.0) and centrifuged (Eppendorf 5414; Brinkmann Instruments, Inc., Westbury, NY) at $10,000 \times g$ for $15 \mathrm{~min}$. The supernatants were collected and stored on ice. Supernatants were assayed for peroxidase activity by the guiacol assay as described by Smit and Dubery (24). Five microliters of supernatant was incubated for $5 \mathrm{~min}$ at $25^{\circ} \mathrm{C}$ with the reaction mix (24), and absorbance was determined at $470 \mathrm{~nm}$ in a spectrophotometer (DU-70; Beckman Coulter, Inc., Fullerton, CA). The reaction mix with $5 \mu$ of heat-inactivated supernatant was used as a blank.

Alternate media for elicitor production. Cultures of $T$. virens strain G6 were prepared as described previously in $100 \mathrm{ml}$ of each of the following media: potato dextrose broth (PDB, Difco Laboratories), Rawlin-Thom medium (RT) (22) and malt extract medium (ME) (25), and WBPM. After 7 days incubation, CFS were collected as described previously, and elicitation activity was determined. Sterile media were used as controls.

Characteristics of elicitation activity. CFS were concentrated by freeze-drying (DuraStop/DuraStop MP R114; FTS Systems Inc., Stone Ridge, NY). Lyophilized material was resuspended in sterile water for a final concentration of five times the concentration of the initial material (CFS5).

To test solubility of the eliciting materials, CFS5 were extracted five times with equal volumes of chloroform. The chloroform fractions were evaporated to dryness on a rotary evaporator (Buchi Rotoevaporator; Brinkman Instruments). The chloroformsoluble fraction was resuspended in a volume of sterile distilled water equal to that of the initial solution. The residual solvent was removed from the aqueous fraction with a rotary evaporator. The chloroform-soluble and aqueous fractions were assayed for terpenoid induction activity as described previously.

Ten-milliliter aliquants of CFS5 were placed into prewarmed $15-\mathrm{ml}$ glass test tubes and incubated in an $80^{\circ} \mathrm{C}$ water bath (Thelco Model 82; Precision Scientific Co., Chicago) for 30 and $60 \mathrm{~min}$. Unheated and heated materials were assayed for terpenoid induction activity.

CFS5 were passed through a series of molecular weight cut-off (MWCO) filters, 10,000 (10K), 5,000 (5K), and 3,000 (3K) (Pall Filtron Corp., Northborough, MA and Lida Mftg. Corp., Kenosha, WI). The material retained by the filter and the material that passed through the filter were brought to initial volume with sterile distilled water and assayed for terpenoid induction activity. According to company literature (Pall Filtron Corp.), for protein retention it is necessary to choose a device with an MWCO that is between three and six times smaller than the molecular weight of the protein to be retained, with optimum retention using a size six times smaller than the protein molecular mass. Thus, for the filters used, the $10 \mathrm{~K}$ MWCO filter would be expected to have optimal retention of proteins of $60 \mathrm{kDa}$ or greater, the $5 \mathrm{~K}$ filter would retain proteins of $30 \mathrm{kDa}$ or greater, and the $3 \mathrm{~K}$ filter would be optimum for retention of proteins of $18 \mathrm{kDa}$ or greater.

CFS5 were treated with various enzymes to further characterize the elicitation activity. All enzymes were added to the CFS at 5 units of enzyme per $\mathrm{ml}$ of culture filtrate. Enzymes suspended in sterile distilled water were used to test for direct activity of the enzymes on seedlings. The enzymes used included $\beta$-glucosidase, proteinase K, protease, and trypsin (Sigma Chemical, St. Louis). Protease, proteinase $\mathrm{K}$, and $\beta$-glucosidase were incubated at $37^{\circ} \mathrm{C}$ and trypsin was incubated at $25^{\circ} \mathrm{C}$ for $2 \mathrm{~h}$ in a shaking water bath $(100 \mathrm{rpm})$. Materials were assayed for terpenoid induction activity.

The protein concentration in the preparations was tested with the Coomassie PlusProtein Assay Kit (Pierce, Rockford, IL). The concentration for two $50-\mu \mathrm{l}$ replicates of each protein preparation was compared according to manufacturer's instructions. Absorbance was determined at $595 \mathrm{~nm}$ in a spectrophotometer and compared with bovine serum albumin standards.

Polyacrylamide gel electrophoresis and western blotting. CFS5 that had been passed through a 10K MWCO filter were fractionated with sodium dodecyl sulfate-polyacrylamide gel electrophoresis (SDS-PAGE) using either a 15 or $18 \%$ resolving gel with $4 \%$ stacking gel (Bio-Rad, Hercules, CA). Size markers were broad range and polypeptide SDS-PAGE molecular weight standards (Bio-Rad). For western blotting, cellulysin (Calbiochem, La Jolla, CA) was suspended in water at $1 \%$ (wt/vol), mixed 1:2 with loading buffer, and included as a control. For western blots, G6-4 CFS5 was double loaded onto the gel. For direct observation, gels were stained with Coomassie blue (Sigma Chemical) or silver stain (Bio-Rad). Bands were transferred to polyvinylidene difluoride (PVDF) membranes (Bio-Rad) for western blot analysis by electrophoretic transfer (Mini TransBlot; Bio-Rad) with Tris-glycine-SDS transfer buffer, $\mathrm{pH} 9.2$ (48 mM Tris, $39 \mathrm{mM}$ glycine, and $0.05 \%$ SDS). In western blots, membranes were blocked overnight with blocking buffer (Trisbuffered saline [TBS] with $0.1 \%$ Tween 20 and $5 \%$ powdered milk) at $4{ }^{\circ} \mathrm{C}$. Blots were probed with antibodies developed against the EIX from T. viride, obtained from J. D. Anderson (Beltsville, MD). Antibodies were diluted 1:10,000 in blocking buffer and incubated for 1 and $3 \mathrm{~h}$ for initial tests. Two sets of blots were incubated overnight to detect low levels of proteins. Blots were washed three times and developed with TBS-Tween for $10 \mathrm{~min}$ each. Washed blots were incubated for $1 \mathrm{~h}$ with goat anti-rabbit alkaline phosphatate conjugate (Bio-Rad) in blocking buffer at room temperature. Blots were washed three times, 10 min each, with TBS-Tween and developed according to manufacturer's instructions (Bio-Rad). When color developed, blots were washed twice for $5 \mathrm{~min}$ each in sterile nano-pure water and air dried.

Activity of fractions. Bands were cut from SDS-PAGE gels. Material in bands was collected by electroelution according to the manufacturer's instructions (422 Electro-Eluter; Bio-Rad), in which case the material was in a denatured form. Alternatively, gel slices (single bands) were macerated in a renaturation buffer (30 mM HEPES buffer, pH 7.0, 0.1\% Tween 80, 10\% glycerol, and $5 \mathrm{mM}$ dithiothreitol), incubated at room temperature for $3 \mathrm{~h}$, and centrifuged for $5 \mathrm{~min}$ at $12,000 \times g$. The supernatant was collected, with the materials in a renatured form. Eluted materials were assayed for activity on cotton seedlings.

Because one fraction described previously showed a crossreaction with the EIX antibody from $T$. viride, cellulysin was assayed for elicitation activity on cotton radicles. Cellulysin was suspended in acetate buffer $(\mathrm{pH} 5.0)$ at a concentration of $0.5 \mathrm{mg} / \mathrm{ml}$, assayed as described previously, and compared with water and acetate buffer controls. 
The $18-\mathrm{kDa}$ band was excised from a PVDF membrane and submitted to the Protein Chemistry Core Laboratory (Baylor College of Medicine, Houston, TX) for amino-terminal sequencing. The amino acid sequence was used in a database homology search using the BLASTp algorithm.

Statistics. All experiments were repeated at least two times. The data from the last trials are presented here. Statistics were performed using the general linear model (version 6; SAS Institute, Cary, NC) or the $t$ test of correlation functions of EXCEL (Microsoft Corp., Bothell, WA).

\section{RESULTS}

CFS from the biocontrol-effective strains of $T$. virens significantly stimulated terpenoid levels in cotton radicles compared with the levels in the water and media-treated controls and the ineffective strain (Table 1). Peroxidase activity was similarly significantly stimulated $(P=0.02)$ in roots treated with extract from the biocontrol-effective strain G6 (11.77 \pm 1.46 pkat $)$ when compared with the ineffective strain G6-4 (8.72 \pm 1.58 pkat). No significant differences $(\alpha=0.05)$ were found between the three different fungal strains in the number of colony-forming units produced in the media.

The levels of terpenoids detected in plants treated with the various media differed. For example, average desoxyhemigossypol (dHG) levels were 2.04, 4.36, 9.98, and $10.22 \mu \mathrm{g} / \mathrm{g}$ of tissue for RT, WBPM, ME, and PDB, respectively. Levels of dHG for media in which G6 had grown were 5.31, 27.16, 21.69, and $12.36 \mu \mathrm{g} / \mathrm{g}$ of tissue for RT, WBPM, ME, and PDB, respectively. The difference in terpenoid levels between the sterile medium control and the media in which G6 had been grown was significant $(\alpha=$ 0.05 ) for filtrates of cultures grown in ME and RT as well as the WBPM, but not in PDB. The G6 culture grown in RT had significantly higher terpenoid levels than material exposed to sterile water (dHG of $2.02 \mu \mathrm{g} / \mathrm{g}$ of tissue).

The elicitation activity for most terpenoids was not found in the chloroform extracts (Table 2) and was retained after heating at $80^{\circ} \mathrm{C}$ for up to $60 \mathrm{~min}$. The elicitor(s) passed through a $5 \mathrm{~K}$ MWCO filter, but not a $3 \mathrm{~K}$ MWCO filter (Table 2), and were highly sensitive to proteinase $\mathrm{K}$ treatment, with less sensitivity to trypsin, $\beta$-glucosidase, and protease treatment (Table 3 ). Of the enzyme preparations, the protease, trypsin, and proteinase $\mathrm{K}$ had significantly $(\alpha=0.05)$ higher levels of hemigossypol in the treated seedlings than in the water control (Table 4), with the highest levels with the protease treatment. However, these levels were still lower than those found with any of the CFS treatments. Significantly higher levels of $\mathrm{dHG}$ and 5-methoxygossypol were

TABLE 1. Stimulation of cotton terpenoids in seedling radicles by treatment with culture filtrates from Trichoderma virens shake cultures

\begin{tabular}{lrrrrrr}
\hline & \multicolumn{6}{c}{ Terpenoid concentration $(\mu \mathrm{g} \text { of compound per g of tissue })^{\mathrm{z}}$} \\
\cline { 2 - 7 } Treatment $^{\mathrm{y}}$ & \multicolumn{1}{c}{$\mathrm{dHG}$} & \multicolumn{1}{c}{ HG } & \multicolumn{1}{c}{ dMHG } & MHG & HGAL & \multicolumn{1}{c}{$\mathrm{G}$} \\
\hline Water & $2.46 \mathrm{a}$ & $2.03 \mathrm{a}$ & $2.63 \mathrm{a}$ & $1.82 \mathrm{a}$ & n.d. & $94.68 \mathrm{a}$ \\
WB+PM & $4.36 \mathrm{a}$ & $14.89 \mathrm{~b}$ & $2.38 \mathrm{a}$ & $3.08 \mathrm{a}$ & $3.88 \mathrm{a}$ & $133.19 \mathrm{a}$ \\
G6-4 & $3.93 \mathrm{a}$ & $10.11 \mathrm{~b}$ & $2.06 \mathrm{a}$ & $2.97 \mathrm{a}$ & $3.25 \mathrm{a}$ & $129.24 \mathrm{a}$ \\
G6 & $27.16 \mathrm{~b}$ & $90.58 \mathrm{c}$ & $10.26 \mathrm{~b}$ & $6.76 \mathrm{~b}$ & $39.96 \mathrm{~b}$ & $250.79 \mathrm{~b}$ \\
\hline
\end{tabular}

${ }^{\mathrm{y}}$ Treatments include water control, filtrate from the wheat bran and peat moss medium (WB+PM) and culture filtrates from $\mathrm{WB}+\mathrm{PM}$ medium in which an ineffective mutant (G6-4) of a biocontrol-effective strain (G6) of $T$. virens had been grown.

${ }^{\mathrm{z}}$ Terpenoids detected included $\mathrm{dHG}=$ desoxyhemigossypol, $\mathrm{HG}=$ hemigossypol, $\mathrm{dMHG}=$ desoxyhemigossypol 6-methyl ether, $\mathrm{MHG}=$ hemigossypol 6-methyl ether, HGAL = hemigossylic acid lactone, and $\mathrm{G}=$ gossypol. Numbers followed by the same letter are not significantly different $(\alpha=0.05)$ according to Fisher's least significant difference. n.d. $=$ not detected; statistics were performed without this treatment when there was no detectable terpenoid production. Numbers are the mean of three replicates of 12 seedlings each.
TABLE 2. Characteristics of elicitation activity from Trichoderma virens culture filtrates $^{\mathrm{w}}$

\begin{tabular}{lrrrrrc}
\hline Treatment $^{\mathrm{x}}$ & dHG & HG & dMHG & MHG & HGAL & G \\
\hline Solubility & & & & & & \\
G6-untreated & $26.56 \mathrm{a}$ & $43.45 \mathrm{a}$ & $4.70 \mathrm{a}$ & $3.27 \mathrm{a}$ & $12.26 \mathrm{a}$ & $191.54 \mathrm{a}$ \\
G6-aqueous & $22.02 \mathrm{a}$ & $30.62 \mathrm{a}$ & $4.53 \mathrm{a}$ & $2.35 \mathrm{a}$ & $8.04 \mathrm{a}$ & $144.44 \mathrm{a}$ \\
G6-chloroform & $6.49 \mathrm{~b}$ & $4.60 \mathrm{~b}$ & $3.20 \mathrm{a}$ & $0.47 \mathrm{~b}$ & n.d. & $101.36 \mathrm{a}$ \\
Size exclusion & & & & & & \\
G6 & $39.05 \mathrm{a}$ & $79.72 \mathrm{a}$ & $15.03 \mathrm{a}$ & $7.38 \mathrm{a}$ & $18.09 \mathrm{a}$ & $300.36 \mathrm{a}$ \\
10K retained & $9.19 \mathrm{~b}$ & $6.62 \mathrm{~b}$ & $4.58 \mathrm{~b}$ & $1.17 \mathrm{a}$ & $2.97 \mathrm{~b}$ & $169.42 \mathrm{~b}$ \\
10K filtrate & $48.89 \mathrm{a}$ & $88.82 \mathrm{a}$ & $18.94 \mathrm{a}$ & $9.81 \mathrm{a}$ & $21.97 \mathrm{a}$ & $343.11 \mathrm{a}$ \\
5K retained & $11.88 \mathrm{~b}$ & $9.94 \mathrm{~b}$ & $6.26 \mathrm{~b}$ & $2.88 \mathrm{a}$ & n.d. & $168.72 \mathrm{~b}$ \\
5K filtrate & $40.83 \mathrm{a}$ & $87.82 \mathrm{a}$ & $15.29 \mathrm{a}$ & $8.81 \mathrm{a}$ & $18.65 \mathrm{a}$ & $332.31 \mathrm{a}$ \\
3K retained & $26.26 \mathrm{a}$ & $53.10 \mathrm{a}$ & $8.19 \mathrm{ab}$ & $5.09 \mathrm{a}$ & $8.93 \mathrm{~b}$ & $244.71 \mathrm{a}$ \\
3K filtrate & $14.13 \mathrm{~b}$ & $12.78 \mathrm{~b}$ & $7.86 \mathrm{~b}$ & $4.52 \mathrm{a}$ & $4.97 \mathrm{~b}$ & $166.55 \mathrm{~b}$ \\
Temperature & & & & & & \\
G6-28 & & & & & & \\
G6- $^{\circ} \mathrm{C}$ & $28.43 \mathrm{a}$ & $46.34 \mathrm{a}$ & $4.25 \mathrm{a}$ & $2.95 \mathrm{a}$ & $8.29 \mathrm{a}$ & $230.46 \mathrm{a}$ \\
& $28.52 \mathrm{a}$ & $29.38 \mathrm{~b}$ & $3.27 \mathrm{a}$ & $2.43 \mathrm{a}$ & $7.65 \mathrm{a}$ & $184.40 \mathrm{a}$ \\
\hline
\end{tabular}

${ }^{\mathrm{w}} \mathrm{dHG}=$ desoxyhemigossypol, $\mathrm{HG}=$ hemigossypol, $\mathrm{dMHG}=$ desoxyhemigossypol 6-methyl ether, $\mathrm{MHG}=$ hemigossypol 6-methyl ether, $\mathrm{HGAL}=$ hemigossylic acid lactone, and $\mathrm{G}=$ gossypol. All values are micrograms of compound per gram of tissue. Numbers followed by the same letter in the same experimental group are not significantly different $(\alpha=0.05)$ according to Fisher's least significant difference. n.d. = not detected; statistics were performed without these treatments for terpenoids for which there was no detectable production.

${ }^{x}$ Treatments are all culture filtrate from wheat bran and peat moss media in which $T$. virens strain G6 had been grown, treated with different solvents, molecular weight cut-off filtration, or incubation at different temperatures.

${ }^{y}$ Retained material remained on the membrane of the given size while the filtrate passed through and was collected following centrifugation. The expected protein molecular mass retained by the filters would be $\geq 60 \mathrm{kDa}$ for the $10 \mathrm{~K}$ filter, $\geq 30 \mathrm{kDa}$ for the $5 \mathrm{~K}$ filter, and $\geq 18 \mathrm{kDa}$ for the $3 \mathrm{~K}$ filter.

${ }^{\mathrm{z}}$ Culture filtrates were incubated at the given temperatures for $60 \mathrm{~min}$. Results were similar for $30 \mathrm{~min}$ incubation (data not shown).

TABLE 3. Effect of enzyme treatment on elicitation activity of Trichoderma virens culture filtrate

\begin{tabular}{lcccccl}
\hline Treatment & dHG & HG & dMHG & MHG & G & MG \\
\hline G6 & 60.99 & 88.09 & 7.66 & 3.39 & 243.19 & 38.91 \\
G6+ $\beta$-glucosidase & 48.62 & 63.02 & $4.17 * *$ & 2.27 & $152.10^{* *}$ & 27.01 \\
G6+protease & 66.87 & 116.98 & 10.11 & 5.11 & $374.05^{* * *}$ & $73.99 * * *$ \\
G6+trypsin & 64.97 & 89.46 & 5.96 & 3.43 & $177.65 *$ & 27.45 \\
G6+proteinase K & $21.46^{* *}$ & $19.20^{* *}$ & $5.43^{*}$ & $1.25^{*}$ & $171.75^{*}$ & 25.57 \\
\hline
\end{tabular}

${ }^{\mathrm{z}}$ Wheat bran and peat moss culture filtrate from T. virens strain G6 incubated with 5 units of enzyme per $\mathrm{ml}$ and assayed on cotton radicles for effect on stimulation of terpenoids, including desoxyhemigossypol (dHG) and hemigossypol (HG) and their respective 6-methyl ether forms (dMHG and MHG), gossypol (G), and 6-methoxygossypol (MG). All values are micrograms of compound per gram of tissue. The enzymes suspended in water served as controls (Table 4). * And ** indicate values significantly lower than untreated extract according to the $t$ test $(-\alpha=0.05$ and 0.01$)$, respectively. *** Indicates values significantly higher than untreated extract according to the $t$ test $(\alpha=0.05)$.

TABLE 4. Effect of water suspensions of enzymes on cotton terpenoids

\begin{tabular}{lcccccc}
\hline Treatment & dHG & HG & dMHG & MHG & G & MG \\
\hline Water & 8.05 & 2.57 & 2.13 & 0.26 & 131.38 & 16.57 \\
B-Glucosidase & 8.45 & 4.05 & 2.25 & 0.33 & 138.75 & 20.35 \\
Protease & $14.58^{*}$ & $12.01^{* *}$ & 2.65 & 0.78 & 153.72 & $27.08^{*}$ \\
Trypsin & 7.18 & $5.23^{*}$ & 2.46 & 0.86 & 164.30 & 12.41 \\
Proteinase K & 6.48 & $6.44^{*}$ & 1.67 & 0.25 & 104.53 & 21.09 \\
\hline
\end{tabular}

${ }^{\mathrm{z}}$ Sterile distilled water alone or with 5 units of enzyme per $\mathrm{ml}$ assayed on cotton radicles for effect on stimulation of terpenoids, including desoxyhemigossypol (dHG) and hemigossypol (HG) and their respective 6-methyl ether forms (dMHG and MHG), gossypol (G), and 6-methoxygossypol (MG). All values are micrograms of compound per gram of tissue.* And ** indicate that values are significantly different than water according to the $t$ test $(-\alpha=0.05$ and 0.01$)$, respectively. 
detected in seedlings treated with protease suspensions, but not the other enzymes. No significant response to $\beta$-glucosidase was seen (Table 4).

When run on SDS-PAGE, several bands were visible in extracts from the biocontrol-effective strains, G6 and G6-5 (Fig. 1), that were not detectable in the ineffective strain, G6-4. Differences in protein levels were confirmed by a protein concentration assay. G6-4 had approximately $80 \mu \mathrm{g}$ of total protein per $\mathrm{ml}$ in the material pass through the 10K MWCO filter, whereas G6 and G65 had approximately 260 to $360 \mu \mathrm{g} / \mathrm{ml}$, respectively. Even when G6-4 CFS5 was double loaded onto a gel (Fig. 1), these bands were not detected.

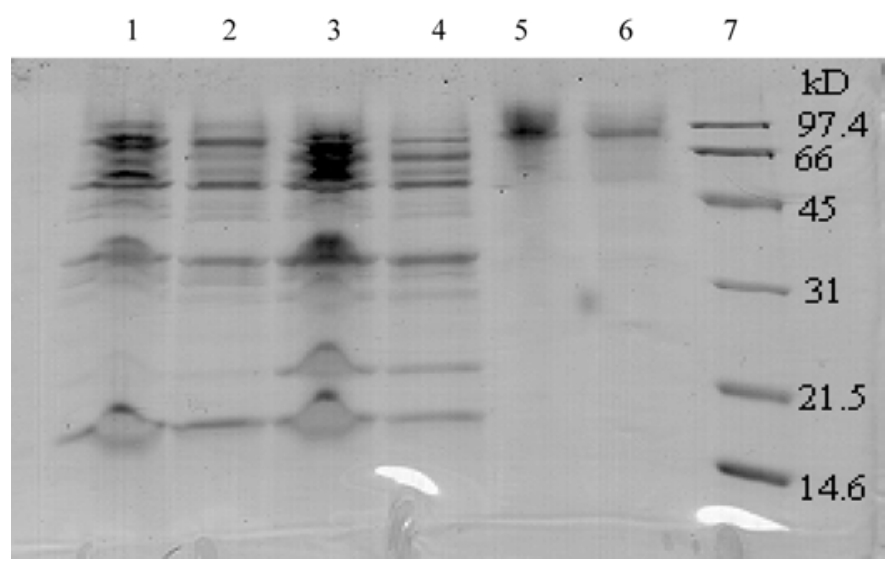

Fig. 1. Sodium dodecyl sulfate-polyacrylamide gel electrophoresis gel of culture filtrates from effective and ineffective biocontrol strains of Trichoderma virens. The gel was stained with Coomassie blue. Several bands are detectable in the effective strains that are absent in ineffective strains. All odd lanes (lanes 1, 3, and 5) were loaded twice with culture filtrate. Lanes 1 and 2, culture filtrate from $T$. virens strain G6 (biocontrol-effective), lanes 3 and 4, culture filtrate from $T$. virens strain G6-5 (biocontrol-effective), lanes 5 and 6, culture filtrate from T. virens strain G6-4 (biocontrol-ineffective), and lane 7 , size marker.

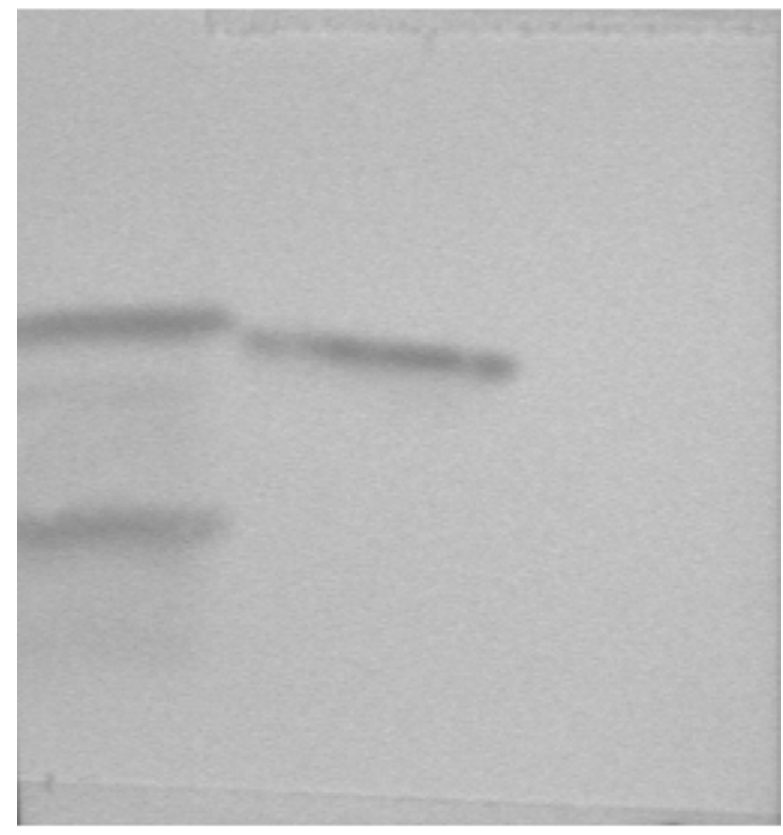

\section{Cellulysin G6 culture filtrate G6-4 culture filtrate}

Fig. 2. Western blot with antiserum for the ethylene-inducing xylanase from Trichoderma viride. A single band of approximately $20 \mathrm{kDa}$ in the biocontrol-active $T$. virens extract cross-reacted with the antibody for the $T$. viride xylanase (3). The second smaller band that showed cross-reaction in cellulysin was not detectable in $T$. virens extract.
Western blot analysis with the antibody for the EIX from $T$. viride showed the two bands reported from $T$. viride in the cellulysin (Fig. 2). A single band was detected in the biocontroleffective $T$. virens, and no bands were detected in the ineffective $T$. virens strain when incubated for 1 or $3 \mathrm{~h}$. When blots were incubated longer $(12 \mathrm{~h})$, a weak band was observed from the ineffective $T$. virens strain (data not shown).

When the material eluted from PAGE gels was tested for elicitation activity, an $18-\mathrm{kDa}$ band was found to be active in both a denatured and a renatured form (Table 5). Three other bands showed activity in a renatured form. A band of approximately $20 \mathrm{kDa}$ was the same size as the band that showed cross-reaction with the EIX antibody.

Cellulysin, a source for the EIX (3), was assayed for activity on cotton seedlings. Significant elicitation was observed for only hemigossypol (Table 6).

When the $18-\mathrm{kDa}$ band was submitted for amino terminal sequencing, the first 19 amino acids at the amino terminus were determined to be DTVSYDTGYDNGSRSLNDV. A database homology search using the BLASTp algorithm was done to compare this sequence with known sequences in the protein database. The highest similarity (63\% identity, $75 \%$ positives) was to a serine proteinase (GenBank pir||PN0172) from Fusarium sporotrichioides. This was followed by $58 \%$ identity, $68 \%$ positives to an allergen aspf 13 precursor from Aspergillus fumagatus (GenBank sp|060022|AF13 ASPFU) and to the protein snodprot1 precursor from Phaeosphaeria nodorum (GenBank sp|074238|SNP1 PHANO) (Fig. 3).

\section{DISCUSSION}

Several bands were visible in CFS from biocontrol-effective strains that were not visible in CFS from the biocontrol-ineffective strain. There was no significant difference in the number

TABLE 5. Induction of cotton phytoalexins in seedling roots with different protein bands from polyacrylamide gel electrophoresis (PAGE)

\begin{tabular}{lccccc}
\hline & \multicolumn{2}{c}{ Renatured $^{\mathrm{z}}$} & & \multicolumn{2}{c}{ Denatured $^{\mathrm{z}}$} \\
\cline { 2 - 3 } \cline { 5 - 6 } Band $^{\mathrm{y}}$ & $\mathrm{dHG}$ & $\mathrm{HG}$ & & $\mathrm{dHG}$ & $\mathrm{HG}$ \\
\hline Buffer & $4.7 \mathrm{~d}$ & $5.0 \mathrm{e}$ & & $3.8 \mathrm{bc}$ & $2.8 \mathrm{~b}$ \\
$6.5 \mathrm{kDa}$ & $10.8 \mathrm{ab}$ & $22.9 \mathrm{ab}$ & & $4.1 \mathrm{~b}$ & $2.6 \mathrm{bc}$ \\
$18 \mathrm{kDa}$ & $12.6 \mathrm{a}$ & $25.6 \mathrm{a}$ & & $7.4 \mathrm{a}$ & $4.5 \mathrm{a}$ \\
$20 \mathrm{kDa}$ & $7.2 \mathrm{~cd}$ & $13.9 \mathrm{~cd}$ & & $4.1 \mathrm{~b}$ & $2.1 \mathrm{bc}$ \\
$26 \mathrm{kDa}$ & $12.2 \mathrm{a}$ & $24.6 \mathrm{a}$ & & $4.5 \mathrm{~b}$ & $4.0 \mathrm{ab}$ \\
$32 \mathrm{kDa}$ & $5.7 \mathrm{~d}$ & $7.1 \mathrm{de}$ & & $2.9 \mathrm{c}$ & $1.8 \mathrm{bc}$ \\
$42 \mathrm{kDa}$ & $10.0 \mathrm{ab}$ & $16.0 \mathrm{bc}$ & & $2.9 \mathrm{c}$ & $1.4 \mathrm{c}$ \\
\hline
\end{tabular}

y Bands were extracted from PAGE gel and either used directly (denatured) or incubated in renaturation buffer before use. Buffer for treatment is the buffer in which the bands were applied to seedlings. Bands were used in either a denatured or a renatured state.

${ }^{\mathrm{z}} \mathrm{dHG}=$ desoxyhemigossypol, $\mathrm{HG}=$ hemigossypol. Values are micrograms of compound per gram of tissue. Numbers followed by the same letter are not significantly different $(\alpha=0.05)$ according to Fisher's least significant difference.

TABLE 6. Effect of cellulysin treatment on cotton radicles ${ }^{2}$

\begin{tabular}{llllllr}
\hline & \multicolumn{5}{c}{ Terpenoid concentration $(\mu \mathrm{g}$ of compound per g of tissue) } \\
\cline { 2 - 6 } Treatment & dHG & HG & dMHG & MHG & HGAL & G \\
\hline Water & n.d. & n.d. & n.d. & n.d. & n.d. & $46.56 \pm 23.60$ \\
Buffer & n.d. & n.d. & n.d. & n.d. & n.d. & $117.47 \pm 64.53$ \\
Cellulysin & n.d. & $2.39 \pm 0.37$ & n.d. & n.d. & n.d. & $103.85 \pm 14.67$ \\
\hline
\end{tabular}

${ }^{\mathrm{z}}$ Assayed water, acetate buffer, or a suspension of $0.5 \mathrm{mg} / \mathrm{ml}$ of cellulysin in acetate buffer on cotton radicles for effect on stimulation of terpenoids, including desoxyhemigossypol (dHG) and hemigossypol (HG) and their respective 6-methyl ether forms (dMHG and MHG), hemigossylic acid lactone (HGAL), and gossypol (G). n.d. = not detected by high-performance liquid chromatography. Numbers are averages followed by the standard deviation. 
of colony-forming units produced by these strains in the culture medium, so this difference is unlikely to be due to differences in fungal growth.

Since the CFS activity was most reduced by treatment with proteinase $\mathrm{K}$, the elicitors are most likely proteins or glycoproteins. The lower level of protein production by the ineffective biocontrol strain compared with the effective strains is further evidence for a role of these materials. The reduced detection of two of the induced compounds following treatment of the CFS with $\beta$-glucosidase may indicate that some of these proteins are glycosylated, and that this glycosylation has a role in activity. When a western blot was tested with antibodies for glycosylation, several bands above $20 \mathrm{kDa}$ in size reacted with the antibody (data not shown).

The size of the bands observed on the SDS-PAGE gels is larger than what might be expected following passage through a $10 \mathrm{~K}$ MWCO membrane. However, the results are consistent with the company's recommendations. The majority of the activity passed through the $5 \mathrm{~K}$ filter but was retained by the $3 \mathrm{~K}$ filter. This would be consistent with the optimal retention of proteins of a molecular mass of $30 \mathrm{kDa}$ or more by the $5 \mathrm{~K}$ filter and of $18 \mathrm{kDa}$ or more by the $3 \mathrm{~K}$ filter, because most of the bands excised from PAGE gels that showed activity were between 18 and $30 \mathrm{kDa}$. These results are consistent with work by Hosono et al. (11) in which material that passed through a 50-kDa cut-off membrane, but not through a 6-kDa cut-off membrane filter, was recorded with sizes between 60 and 2,460 $\mathrm{kDa}$.

The base level of the terpenoids in the cotton radicles varied in different experiments (Tables 1 to 5 ; [14]). This may be due to differing levels in the seeds used for the tests, or to other factors. The buffers used in some of the experiments also may have affected these levels. For example, the terpenoid levels in radicles were consistently lower in the tests with materials extracted from PAGE gels (Table 4), which were in buffers, as opposed to those in which the materials were in water or media (Tables 1 to 4).

Glycoproteins and glycopeptides with elicitation activity have been reported from a number of fungi and oomycetes (review in literature citation 9). Some of these are from cell wall fractions (17), rather than culture filtrate like our elicitor fraction. Other known fungal or oomycetous elicitors include the elicitins from Phytophthora spp, which are holoproteins with molecular masses of about $10 \mathrm{kDa}(16,20,21)$. Unlike the elicitor(s) reported here, the elicitins cause necrosis of tobacco and other plants within $24 \mathrm{~h}$ of application (21). No necrosis of cotton was observed within $24 \mathrm{~h}$ with our elicitors, but our elicitors were applied to roots rather than leaves. However, the cotyledons came into contact with the material saturating the filter paper, and no difference in necrosis was observed in cotyledons between those exposed to sterile water and those exposed to the CFS.

One band from $T$. virens cross-reacted with the EIX antibody, indicating that this band has antigenic similarity to the EIX in $T$. viride. However, this band migrated slightly farther on the SDSPAGE gel than did the larger EIX fraction in T. viride, thus it may be smaller than the $T$. viride EIX. The crude CFS from $T$. virens had xylanase activity (data not shown). In a renatured form, this band (Table 4, band 20) elicited some terpenoid production in cotton roots, indicating that this may be an elicitor similar to the EIX in T. viride. However, cellulysin, which contains EIX (3 and
Fig. 2), produced significant elicitation of only one of the phytoalexins in cotton seedlings (Table 5). This weak induction indicates that this band is not the major elicitor in $T$. virens. There was a weak band observed after incubation overnight of the EIX antibody with the extract from the ineffective T. virens strain. This strain also had xylanase activity, but at significantly lower levels than did the effective strains $(P=0.03)$. Because there was no difference in the growth of these strains, as indicated by production of colony-forming units, these results indicate that the ineffective strain produced lower levels of the EIX-type material than did the biocontrol-effective strains.

An $18-\mathrm{kDa}$ protein was isolated from the culture filtrate of $T$. virens and elicited defense responses in cotton seedling roots in either a denatured or renatured form. This gave the strongest and most consistent elicitation of any of the bands tested. This band did not cross-react with the EIX antibody, indicating that it is a different elicitor. The evidence above indicates that this may be a novel elicitor from $T$. virens. The amino-terminal end of this protein had highest similarity (63\% identity) to a serine proteinase from Fusarium sporotrichioides. However, no putative conserved domains were detected, so the similarity to the serine proteinase is unlikely to be at an active site. The material was not tested for serine proteinase activity. Serine proteinases have been detected from other plant-associated fungi (23).

\section{LITERATURE CITED}

1. Calderon, A. A., Zapata, J. M., Munoz, R., Pedreno, M. A., and Barcelo, A. R. 1993. Resveratrol production as a part of the hypersensitive-like response of grapevine cells to an elicitor from Trichoderma viride. New Phytol. 124:455-463.

2. Coleman, M. J., Mainzer, J., and Dickerson, A. G. 1992. Characterization of a fungal glycoprotein that elicits a defense response in French bean. Physiol. Mol. Plant Pathol. 40:333-351.

3. Dean, J. F. D., and Anderson, J. D. 1991. Ethylene biosynthesis-inducing xylanase. Plant Physiol. 95:316-323.

4. Dean, J. F. D., Gamble, H. R., and Anderson, J. D. 1989. The ethylene biosynthesis-inducing xylanase: Its induction in Trichoderma viride and certain plant pathogens. Phytopathology 79:1071-1078.

5. De Meyer, G., Bigirimana, J., Elad, Y., and Hofte, M. 1998. Induced systemic resistance in Trichoderma harzianum T39 biocontrol of Botrytis cinerea. Eur. J. Plant Pathol. 104:279-286.

6. De Wit, P. J. G. M., Hofman, A. E., Velthuis, G. C. M., and Kuć, J. A. 1985. Isolation and characterization of an elicitor of necrosis isolated from intercellular fluids of compatible interactions of Cladosporium fulvum (syn. Fulvia fulva) and tomato. Plant Physiol. 77:642-647.

7. Dubery, I. A., and Slater, V. 1997. Induced defense responses in cotton leaf disks by elicitors from Verticillium dahliae. Phytochemistry 44:14291434.

8. Grand, C., Sarni, F., and Lamb, C. J. 1987. Rapid induction by fungal elicitor of the synthesis of cinnamyl-alcohol dehydrogenase, as specific enzyme of lignin synthesis. Eur. J. Biochem. 169:73-77.

9. Hahn, M. G. 1996. Microbial elicitors and their receptors in plants. Annu. Rev. Phytopathol. 34:387-412.

10. Hanson, L. E. 2000. Reduction of Verticillium wilt symptoms in cotton following seed treatment with Trichoderma virens. J. Cotton Sci. 4:224231.

11. Hosono, A., Lee, J., Ametani, A., Natsume, M., Hirayama, M., Adachi, T., and Kaminogawa, S. 1997. Characterization of a water-soluble polysaccharide fraction with immunopotentiating activity from Bifidobacterium adolescentis M101-4. Biosci. Biotechnol. Biochem. 61:312-316.

12. Howell, C. R. 1982. Effect of Gliocladium virens on Pythium ultimum, Rhizoctonia solani, and damping-off of cotton seedlings. Phytopathology 72:496-498.

\section{Amino terminal from $T$. virens 18 -kDa protein Serine proteinase from Fusarium sporotrichioides Allergen aspf13 precursor from Aspergillus fumigatus Snodprot1 precursor from Phaeosphoeria nodorum}

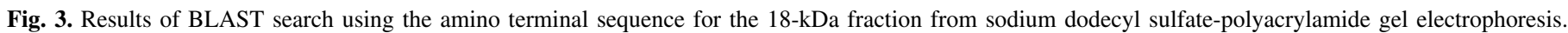
Amino acids common between the $18-\mathrm{kDa}$ fraction and other proteins are highlighted in gray. 
13. Howell, C. R., DeVay, J. E., Garber, R. H., and Batson, W. E. 1997. Field control of cotton seedling diseases with Trichoderma virens in combination with fungicide seed treatments. J. Cotton Sci. 1:15-20.

14. Howell, C. R., Hanson, L. E., Stipanovic, R. D., and Puckhaber, L. S. 2000. Induction of terpenoid synthesis in cotton roots and control of Rhizoctonia solani by seed treatment with Trichoderma virens. Phytopathology 90:248-252.

15. Howell, C. R., Stipanovic, R. D., and Lumsden, R. D. 1993. Antibiotic production by strains of Gliocladium virens and its relation to the biocontrol of cotton seedling diseases. Biocontrol Sci. Technol. 3:435441.

16. Huet, J. C., Nespoulous, C., and Pernollet, J. C. 1992. Structures of elicitin isoforms secreted by Phytophthora drechsleri. Phytochemistry 31:1471-1476

17. Kogel, G., Beissmann, B., Reisener, H. J., and Kogel, K. H. 1988. A single glycoprotein from Puccinia graminis $\mathrm{f}$. sp. tritici cell walls elicits the hypersensitive lignification response in wheat. Physiol. Mol. Plant Pathol. 33:173-185.

18. Koike, N., Hyakumachi, M., Kageyama, K., Tsuyumu, S., and Doke, N. 2001. Induction of systemic resistance in cucumber against several diseases by plant growth-promoting fungi: Lignification and superoxide generation. Eur. J. Plant Pathol. 107:523-533.

19. Madi, L., and Katan, J. 1998. Penicillium janczewskii and its metabolites, applied to leaves, elicit systemic acquired resistance to stem rot caused by Rhizoctonia solani. Physiol. Mol. Plant Pathol. 53:163-175.
20. Nespoulous, C., Huet, J. C., and Pernollet, J. C. 1992. Structure-function relationships of $\alpha$ and $\beta$ elicitins, signal proteins involved in the plantPhytophthora interaction. Planta 186:551-557.

21. Pernollet, J. C., Sallantin, M., Salle-Tourne, M., and Huet, J. C. 1993. Elicitin isoforms from seven Phytophthora species: Comparison of their physico-chemical properties and toxicity to tobacco and other plant species. Physiol. Mol. Plant Pathol. 42:53-67.

22. Raper, K. B., and Thom, C. 1949. Manual of the Penicillia. Williams \& Wilkins, Baltimore, MD.

23. Reddy, P. V., Lam, C. K., and Belanger, F. C. 1996. Mutualistic fungal endophytes express a proteinase that is homologous to proteases suspected to be important in fungal pathogenicity. Plant Physiol. 111:1209-1218.

24. Smit, F., and Dubery, I. A. 1997. Cell wall reinforcement in cotton hypocotyls in response to a Verticillium dahliae elicitor. Phytochemistry 44:811-815.

25. Tuite, J. 1969. Plant Pathological Methods. Burgess Publishing, Minneapolis, MN

26. Zhang, J., Howell, C. R., and Starr, J. L. 1996. Suppression of Fusarium colonization of cotton roots and Fusarium wilt by seed treatments with Gliocladium virens and Bacillus subtilis. Biocontrol Sci. Technol. 6:175187.

27. Zhang, J., Mace, M. E., Stipanovic, R. D., and Bell, A. A. 1993. Production and fungitoxicity of the terpenoid phytoalexins in cotton inoculated with Fusarium oxysporum f. sp. vasinfectum. J. Phytopathol. 139:247-252. 